\title{
Cause, timing, and location of death in the Single Ventricle Reconstruction trial
}

\author{
Richard G. Ohye, MD, ${ }^{a}$ Julie V. Schonbeck, MSN, C-PNP, ${ }^{b}$ Pirooz Eghtesady, MD, PhD, ${ }^{c}$ \\ Peter C. Laussen, MBBS, ${ }^{\mathrm{d}}$ Christian Pizarro, MD, ${ }^{\mathrm{e}}$ Peter Shrader, MA, ${ }^{\mathrm{b}}$ Deborah U. Frank, MD, PhD, ${ }^{\mathrm{f}}$ \\ Eric M. Graham, MD, ${ }^{\mathrm{g}}$ Kevin D. Hill, MD, ${ }^{\mathrm{h}}$ Jeffrey P. Jacobs, MD, ${ }^{\mathrm{i}}$ Kirk R. Kanter, MD, ${ }^{\mathrm{j}}$ \\ Joel A. Kirsh, MD, ${ }^{k}$ Linda M. Lambert, MSN-cFNP, ${ }^{\mathrm{f}}$ Alan B. Lewis, MD, ${ }^{1}$ Chitra Ravishankar, MD, ${ }^{\mathrm{m}}$ \\ James S. Tweddell, MD, ${ }^{\mathrm{n}}$ Ismee A. Williams, MD, MS, ${ }^{\mathrm{a}}$ and Gail D. Pearson, MD, ScD, ${ }^{\mathrm{p}}$ for the Pediatric \\ Heart Network Investigators
}

Objectives: The Single Ventricle Reconstruction trial randomized 555 subjects with a single right ventricle undergoing the Norwood procedure at 15 North American centers to receive either a modified Blalock-Taussig shunt or right ventricle-to-pulmonary artery shunt. Results demonstrated a rate of death or cardiac transplantation by 12 months postrandomization of $36 \%$ for the modified Blalock-Taussig shunt and $26 \%$ for the right ventricle-to-pulmonary artery shunt, consistent with other publications. Despite this high mortality rate, little is known about the circumstances surrounding these deaths.

Methods: There were 164 deaths within 12 months postrandomization. A committee adjudicated all deaths for cause and recorded the timing, location, and other factors for each event.

Results: The most common cause of death was cardiovascular (42\%), followed by unknown cause (24\%) and multisystem organ failure $(7 \%)$. The median age at death for subjects dying during the 12 months was 1.6 months (interquartile range, 0.6 to 3.7 months), with the highest number of deaths occurring during hospitalization related to the Norwood procedure. The most common location of death was at a Single Ventricle Reconstruction trial hospital $(74 \%)$, followed by home (13\%). There were 29 sudden, unexpected deaths (18\%), although in retrospect, 12 were preceded by a prodrome.

Conclusions: In infants with a single right ventricle undergoing staged repair, the majority of deaths within 12 months of the procedure are due to cardiovascular causes, occur in a hospital, and within the first few months of life. Increased understanding of the circumstances surrounding the deaths of these single ventricle patients may reduce the high mortality rate. (J Thorac Cardiovasc Surg 2012;144:907-14)

Despite medical and surgical advances, patients with hypoplastic left heart syndrome and other related single right

\footnotetext{
From the University of Michigan Medical School, ${ }^{a}$ Ann Arbor, Mich; New England Research Institutes, ${ }^{\mathrm{b}}$ Watertown, Mass; Cincinnati Children's Medical Center, ${ }^{\mathrm{c}}$ Cincinnati, Ohio; Children's Hospital Boston, ${ }^{\mathrm{d}}$ Boston, Mass; Alfred I. duPont Hospital for Children, ${ }^{\mathrm{e}}$ Wilmington, Del; University of Utah School of Medicine, ${ }^{\mathrm{f}}$ Salt Lake City, Utah; Medical University of South Carolina, ${ }^{\mathrm{g}}$ Charleston, SC; Duke University Medical Center, ${ }^{\text {h }}$ Durham, NC; Congenital Heart Institute of Florida, ${ }^{\mathrm{i}}$ St Petersburg, Fla; Emory University School of Medicine, ${ }^{j}$ Atlanta, Ga; Hospital for Sick Children, ${ }^{k}$ Toronto, Ontario, Canada; Children's Hospital Los Angeles, ${ }^{1}$ Los Angeles, Calif; Children's Hospital of Philadelphia, ${ }^{\mathrm{m}}$ Philadelphia, Pa; Children's Hospital of Wis-

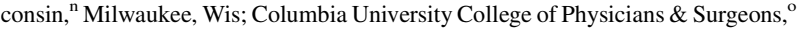
New York, NY; and National Heart, Lung, and Blood Institute, ${ }^{\mathrm{p}}$ Bethesda, Md.

This study was supported by U01 grants from the National Heart, Lung, and Blood Institute (Nos. HL068269, HL068270, HL068279, HL068281, HL068285, HL068292, HL068290, HL068288, and HL085057).

Disclosures: Authors have nothing to disclose with regard to commercial support.

The contents of this article are solely the responsibility of the authors and do not necessarily represent the official views of National Heart, Lung, and Blood Institute or the National Institutes of Health.

Received for publication Oct 28, 2011; revisions received March 15, 2012; accepted for publication April 13, 2012; available ahead of print Aug 17, 2012.

Address for reprints: Richard G. Ohye, MD, University of Michigan Medical School, 5144 CVC, 1500 E Medical Center Dr/SPC 5864, Ann Arbor, MI 48109-5864 (E-mail: ohye@umich.edu).

0022-5223/\$36.00

Copyright (C) 2012 by The American Association for Thoracic Surgery

http://dx.doi.org/10.1016/j.jtcvs.2012.04.028
}

ventricle malformations experience the highest risk of mortality of any common form of congenital heart disease. ${ }^{1-5}$ Staged palliation for these patients requires 3 procedures, including the Norwood procedure at the time of birth, a superior cavopulmonary anastomosis (stage II) at 4 to 6 months of age, and a Fontan procedure at age 12 to 48 months.

The Norwood procedure remains the procedure with the highest risk of mortality during staged repair. ${ }^{1-4,6}$ It has been postulated that the modified Blalock-Taussig shunt (MBTS) traditionally used to supply pulmonary blood flow at the Norwood procedure contributes to this high mortality due to diastolic run-off into the pulmonary circulation and ensuing coronary insufficiency. ${ }^{7,8}$ Alternatively, a right ventricle-to-pulmonary artery shunt (RVPAS), as initially described by Norwood in 1981 and recently popularized by Sano and colleagues, ${ }^{4}$ can be utilized as the source of pulmonary blood flow for the Norwood procedure. The RVPAS does not result in continued forward flow during diastole, but requires an incision in the outflow tract of the only functional ventricle. ${ }^{8}$ The 2 shunts have been compared in small case series with limited follow-up that demonstrated conflicting results for hospital survival. ${ }^{1-4,9}$ 


\section{Abbreviations and Acronyms}

MBTS $=$ modified Blalock-Taussig shunt

RVPAS $=$ right ventricle-to-pulmonary artery shunt SVR $=$ single ventricle reconstruction

The Single Ventricle Reconstruction (SVR) trial (for a list of participating centers and investigators, see Appendix 1) (ClinicalTrials.gov unique identifier: NCT00115934) randomized patients with a morphologic single right ventricle to receive either a MBTS or RVPAS during the Norwood procedure. $^{8,10}$ The National Heart, Lung, and Blood Institute-funded trial enrolled 555 subjects from 15 North American centers from May 2005 to July 2008 through the Pediatric Heart Network. The primary end point of the trial was the rate of death or cardiac transplantation 12 months after randomization based on intention-to-treat analysis. As reported previously, ${ }^{6}$ there were 72 events $(26.3 \%)$ (ie, 68 deaths and 4 transplantations) in the RVPAS cohort, compared with 100 events $(36.4 \%)$ (ie, 91 deaths and 9 transplantations) among the subjects receiving an MBTS. The group difference of $10.1 \%$ favored the RVPAS (95\% confidence interval, 17.8-2.4; $P=.01$ ). The nonintention-to-treat analysis, based on the actual shunt in place at the conclusion of the Norwood procedure (MBTS $\mathrm{n}=268$ vs RVPAS $\mathrm{n}=281$ ), showed similar results, with a lower rate of death or cardiac transplantation at 12 months in the RVPAS group ( $25.6 \%$ vs $37.3 \%$; absolute reduction of $11.7 \%$; 95\% CI, 19.4-4.0; $P=.003$ ).

Findings in the SVR trial are consistent with previously reported mortality rates of $7 \%$ to $19 \%$ for the Norwood hospitalization and $4 \%$ to $15 \%$ between the Norwood hospital discharge and the stage II operation (interstage period). ${ }^{1-5}$ Despite the high mortality associated with staged palliation for single ventricle lesions, little is known about the specific causes, timing, and location of deaths during the first year. Improved understanding of the circumstances surrounding the mortality of these infants may allow for refinements in management to optimize outcomes for this challenging population of patients. The SVR trial, which included prospective follow-up of subjects, provides a unique opportunity to explore mortality-related events in this high-risk population. The purpose of our report is to describe the subjects in this well-defined cohort.

\section{METHODS}

\section{Study Sample}

Of the 555 subjects enrolled in the SVR trial, six were excluded from the primary end point, yielding a final cohort of 549; 5 infants did not undergo a Norwood procedure after randomization and 1 patient's family withdrew research consent following the Norwood procedure. The 549 eligible subjects from the SVR trial formed the analytic cohort for this report. Each participating center's institutional review board approved the trial, and written informed consent was obtained from one or both parents. Vital status; date of death; a narrative of the circumstances surrounding the death, including location; and, if performed, the autopsy results, were collected as part of the SVR trial protocol. These data were extracted from the trial database for analysis. Additional information, such as results of the most recent echocardiogram before death, was obtained as needed to assist adjudication of the cause of death.

\section{Adjudication Process}

All deaths that occurred during the 12 months following randomization were reviewed by a 5-member panel recruited from participating SVR centers and the National Heart, Lung, and Blood Institute. The panel included the SVR study chairman, a pediatric cardiologist, a pediatric cardiac intensivist, and 2 pediatric cardiac surgeons. A list of cause of death categories (Table 1) was developed by the panel, with input from the SVR trial subcommittee, which included a representative from each participating center. Further subcategorization within categories, beyond for example "cardiovascular" to "shunt," was not practical due to the relatively small numbers of deaths within each category. In addition, although it was often possible to assign a death to the "cardiovascular" category, it was extremely rare to have definite objective data pointing to a more specific cause; for example, to a shunt thrombosis defined at autopsy or on angiography.

Each panel member reviewed the information on each death independently and assigned the death to 1 category. The panel discussed each case via conference call to arrive at a consensus decision on the final categorization. If death occurred in an operating room, an intensive care unit, a general care ward, an emergency room, at another facility, or at home was recorded. The number of deaths in which care was withdrawn and the number of cases with an autopsy were also noted.

A subgroup of interest included those subjects who died unexpectedly after being discharged to home in good condition. An entry was recorded if the patient had been doing well at home and suffered an acute event leading to death. In addition, the medical charts were reviewed to investigate if any prodrome, such as poor oral intake or irritability, could be identified. For the purposes of our analysis, a prodrome was defined as a sign or symptom that occurred in the days preceding an event that could have offered the potential for intervention to prevent death (eg, not including a patient who became acutely cyanotic and then immediately arrested).

\section{Statistical Methods}

Comparisons by shunt type were conducted according to the shunt in place at the end of the Norwood procedure (ie, nonintention-to-treat). A small number of pulmonary parenchymal, pulmonary vascular, and airway deaths occurred and these were combined into 1 single pulmonary category. Multisystem organ failure with infectious etiology and with other/unknown etiology was also combined into a single category for similar reasons. The Fisher exact test was used to compare the distributions of cause of death by shunt type and by time period. A secondary analysis was performed comparing the proportions of patients with cardiovascular vs noncardiovascular death by shunt type. Comparisons of the cause of death distributions by shunt type were also conducted within strata defined by the presence vs absence of aortic atresia, and the presence vs absence of obstructed pulmonary venous return, which were prespecified, prerandomization strata in the SVR trial. Patient characteristics of those with unknown cause of death were compared with those with a known cause of death using the Student $t$ test for continuous variables and the Fisher exact test for categorical variables. The median time of death was compared by shunt type using the Wilcoxon rank sum test. Survival probabilities up to 1 year postrandomization by shunt type were estimated using the Kaplan-Meier method. Qualifying events included posttransplant deaths. All statistical analyses were conducted using SAS version 9.3 (2011; SAS Institute, Cary, NC). 
TABLE 1. Cause of death categories

\begin{tabular}{|c|c|}
\hline Body system & Guidelines \\
\hline Cardiovascular & $\begin{array}{l}\text { Including heart, great vessels, } \\
\text { pulmonary veins, venae cavae, and } \\
\text { shunt }\end{array}$ \\
\hline \multicolumn{2}{|l|}{ Pulmonary } \\
\hline Parenchymal & eg, Bronchopulmonary dysplasia \\
\hline Vascular & $\begin{array}{l}\text { eg, Pulmonary vascular obstructive } \\
\text { disease }\end{array}$ \\
\hline Airway & eg, Airway occlusion, bronchospasm \\
\hline Gastrointestinal/hepatic & Including necrotizing enterocolitis \\
\hline \multicolumn{2}{|l|}{ Renal } \\
\hline Hematologic & $\begin{array}{l}\text { Including documented } \\
\text { hypercoagulable state }\end{array}$ \\
\hline Surgical complication & $\begin{array}{l}\text { Documented technical misadventure } \\
\text { directly related to surgical } \\
\text { procedure (ie, lacerating the aorta } \\
\text { or heart on resternotomy, autopsy } \\
\text { proven stenosis of the coronary } \\
\text { anastomosis). Surgical } \\
\text { complications would not include } \\
\text { routine risks of surgery. }\end{array}$ \\
\hline Catheterization complication & $\begin{array}{l}\text { Documented technical complication } \\
\text { directly related to catheterization } \\
\text { procedure (ie, perforating the left } \\
\text { atrium, or rupturing the pulmonary } \\
\text { artery). Catheterization } \\
\text { complications would not include } \\
\text { routine risks of catheterization. }\end{array}$ \\
\hline $\begin{array}{l}\text { Multisystem organ failure } \\
\text { Infectious etiology } \\
\text { Unknown/other etiology }\end{array}$ & \\
\hline \multicolumn{2}{|l|}{ Infectious } \\
\hline Other & $\begin{array}{l}\text { Used when a specific cause of death is } \\
\text { known, but it does not meet one of } \\
\text { the categories on the list (eg, car } \\
\text { accident). }\end{array}$ \\
\hline Unknown & $\begin{array}{l}\text { The cause of death is unknown due to } \\
\text { lack of information, or a single } \\
\text { causative etiology cannot be } \\
\text { determined. }\end{array}$ \\
\hline
\end{tabular}

\section{RESULTS}

\section{Adjudication Process}

The adjudication process was validated by readjudicating 30 randomly selected deaths. The panel used the same procedure as described above to categorize each death. The prespecified criterion for acceptable agreement was a $\kappa$ statistic value of 0.5 for the lower limit of a 1 -sided $85 \%$ confidence interval. The $\kappa$ statistic was 0.82 (lower $85 \%$ confidence limit, 0.74 ), demonstrating very good agreement between the original cause of death category and the new category for the 30 cases.

\section{Mortality}

One-year follow-up was available on all subjects. Among the 549 subjects, there were 164 deaths $(30 \%)$ during the
TABLE 2. Cause of death in the overall cohort and by shunt type

\begin{tabular}{lccc}
\hline \multicolumn{1}{c}{ Cause of death } & $\begin{array}{c}\text { Overall }(\%) \\
(\mathbf{N}=\mathbf{1 6 4})\end{array}$ & $\begin{array}{c}\text { MBTS }(\%) \\
(\mathbf{n}=\mathbf{9 5})\end{array}$ & $\begin{array}{c}\text { RVPAS (\%) } \\
(\mathbf{n}=\mathbf{6 9})\end{array}$ \\
\hline Cardiovascular & $68(42)$ & $36(38)^{*}$ & $32(46)^{*}$ \\
Unknown & $40(24)$ & $30(32)^{*}$ & $10(14)^{*}$ \\
MSOF, any etiology & $15(9)$ & $7(7)^{*}$ & $8(12)^{*}$ \\
Infection & $11(7)$ & $6(6)^{*}$ & $5(7)^{*}$ \\
Surgical complication & $10(6)$ & $5(5)^{*}$ & $5(7)^{*}$ \\
Pulmonary, any etiology & $9(6)$ & $5(5)^{*}$ & $4(6)^{*}$ \\
Other & $6(4)$ & $2(2)^{*}$ & $4(6)^{*}$ \\
Neurological & $2(1)$ & $2(2)^{*}$ & $0(0)^{*}$ \\
GI/hepatic & $2(1)$ & $1(1)^{*}$ & $1(2)^{*}$ \\
Renal & $1(1)$ & $1(1)^{*}$ & $0(0)^{*}$ \\
Total for all causes other & $96(58)$ & $59(62) \dagger$ & $37(54) \dagger$ \\
$\quad$ than cardiovascular & & & \\
\hline Da & & & \\
\hline
\end{tabular}

Data are presented as number ( $\%)$. Percentages may not total $100 \%$ due to rounding. $M B T S$, Modified Blalock-Taussig shunt; RVPAS, right ventricle-to-pulmonary artery shunt; $M S O F$, multisystem organ failure; GI, gastrointestinal. $* P=.27$ for cause of death by shunt type. $\dagger P=.34$ for cause of death by shunt type.

12 months following randomization. These included the 159 deaths accounted for in the primary outcome from the SVR trial (ie, death or transplantation at 12 months postrandomization), as well as an additional 5 deaths occurring after transplantation but within the 12-month period. By shunt type at the end of the Norwood procedure, there were 69 of 274 deaths $(25 \%)$ in the RVPAS group and 95 of 275 deaths $(35 \%)$ in the MBTS group at 12 months postrandomization. As in the nonintention-to-treat analysis for the primary end point of death or transplantation from the SVR trial, the difference in the nonintention-to-treat analysis for mortality alone was statistically significant, favoring the RVPAS $(P=.007)$.

\section{Cause of Death}

For the overall cohort, as well as when stratified by shunt type, the most common causes of death were of cardiovascular origin, followed by an unknown cause and multisystem organ failure of any etiology (Table 2). To determine if subjects in the unknown category should remain in the analyses, comparisons were conducted between subjects with a known $(n=124)$ vs an unknown cause of death $(\mathrm{n}=40)$. Subjects in the unknown category had a significantly higher mean birth weight $(P=.009)$, were less frequently born at $<37$ weeks gestation $(P=.02)$, and were less likely to have received a RVPAS $(P=.02)$. Exclusion of subjects falling into the unknown cause of death category would therefore result in a biased analytic cohort that is more likely to have a RVPAS and on average has worse birth outcomes. Therefore, subjects in the unknown category were retained in the analysis.

There was no difference in the distribution of the causes of death between the 2 shunt types $(P=.27)$ (Table 2). Similarly, when cause of death was analyzed by comparing cardiovascular causes with all noncardiovascular etiologies, 
TABLE 3. Cause of death by the presence or absence of aortic atresia or obstructed pulmonary venous return, overall, and by shunt type

\begin{tabular}{|c|c|c|c|c|c|c|c|c|c|c|c|c|}
\hline \multirow[b]{2}{*}{ Cause of death } & \multicolumn{2}{|c|}{$\begin{array}{c}\text { Overall } \\
(\mathrm{N}=164) \\
(P=.30)\end{array}$} & \multicolumn{2}{|c|}{$\begin{array}{c}\text { MBTS } \\
(\mathrm{n}=95) \\
(P=.25)\end{array}$} & \multicolumn{2}{|c|}{$\begin{array}{c}\text { RVPAS } \\
(\mathrm{n}=69) \\
(P=.75)\end{array}$} & \multicolumn{2}{|c|}{$\begin{array}{c}\text { Overall } \\
(\mathrm{N}=164) \\
(P=.26)\end{array}$} & \multicolumn{2}{|c|}{$\begin{array}{c}\text { MBTS } \\
(\mathrm{n}=95) \\
(P=.34)\end{array}$} & \multicolumn{2}{|c|}{$\begin{array}{c}\text { RVPAS } \\
(\mathrm{n}=69) \\
(P=.26)\end{array}$} \\
\hline & $\begin{array}{c}\mathbf{A A} \\
(\mathbf{n}=\mathbf{1 0 3})\end{array}$ & $\begin{array}{c}\text { No AA } \\
(n=61)\end{array}$ & $\begin{array}{c}\text { AA } \\
(n=62)\end{array}$ & $\begin{array}{c}\text { No AA } \\
(\mathbf{n}=\mathbf{3 3})\end{array}$ & $\begin{array}{c}\mathbf{A A} \\
(\mathbf{n}=\mathbf{4 1})\end{array}$ & $\begin{array}{l}\text { No AA } \\
(n=28\end{array}$ & $\begin{array}{c}\text { OPVR } \\
(n=14)\end{array}$ & $\begin{array}{c}\text { No OPVR } \\
(\mathbf{n}=\mathbf{1 5 0})\end{array}$ & $\begin{array}{c}\begin{array}{c}\text { OPVR } \\
(n=11)\end{array} \\
\end{array}$ & $\begin{array}{c}\text { No OPVR } \\
(n=84)\end{array}$ & $\begin{array}{l}\text { OPVR } \\
(\mathbf{n}=\mathbf{3})\end{array}$ & $\begin{array}{c}\text { No OPVR } \\
(n=66)\end{array}$ \\
\hline Cardiovascular & $41(40)$ & $27(44)$ & $24(39)$ & $12(36)$ & $17(42)$ & $15(54)$ & $6(43)$ & $62(41)$ & $5(46)$ & $31(37)$ & $1(33)$ & $31(47)$ \\
\hline Unknown & $29(28)$ & $11(18)$ & $22(36)$ & $8(24)$ & 7 (17) & $3(11)$ & $1(7)$ & $39(26)$ & $1(9)$ & $29(34)$ & $0(0)$ & $10(15)$ \\
\hline MSOF, any etiology & $9(9)$ & $6(10)$ & $4(6)$ & $3(9)$ & $5(12)$ & $3(11)$ & $1(7)$ & $14(9)$ & $1(9)$ & $6(7)$ & $0(0)$ & $8(12)$ \\
\hline Infection & $8(8)$ & $3(5)$ & $4(6)$ & $2(6)$ & $4(10)$ & $1(4)$ & $1(7)$ & $10(7)$ & $1(9)$ & $5(4)$ & $0(0)$ & $5(7)$ \\
\hline Surgical complication & $7(7)$ & $3(5)$ & $4(6)$ & $1(3)$ & $3(7)$ & $2(7)$ & $3(21)$ & $7(5)$ & $2(18)$ & $3(4)$ & $1(33)$ & $4(6)$ \\
\hline Pulmonary, any etiology & $4(4)$ & $5(8)$ & $1(2)$ & $4(12)$ & $3(7)$ & $1(4)$ & $1(7)$ & $8(5)$ & $1(9)$ & $4(5)$ & $0(0)$ & $4(6)$ \\
\hline Other & $2(2)$ & $4(7)$ & $1(2)$ & $1(3)$ & $1(2)$ & $3(11)$ & $1(7)$ & $5(3)$ & $0(0)$ & $2(2)$ & $1(33)$ & $3(5)$ \\
\hline Neurologic & $0(0)$ & $2(6)$ & $0(0)$ & $0(0)$ & $0(0)$ & $2(6)$ & $0(0)$ & $2(1)$ & $0(0)$ & $2(2)$ & $0(0)$ & $0(0)$ \\
\hline GI/hepatic & $1(1)$ & $0(0)$ & $1(2)$ & $0(0)$ & $1(1)$ & $0(0)$ & $0(0)$ & $2(1)$ & $0(0)$ & $1(1)$ & $0(0)$ & $1(2)$ \\
\hline Renal & $1(2)$ & $0(0)$ & $0(0)$ & $0(0)$ & $1(2)$ & $0(0)$ & $0(0)$ & $1(1)$ & $0(0)$ & $1(1)$ & $0(0)$ & $0(0)$ \\
\hline
\end{tabular}

Data are presented as number (\%). Percentages may not total $100 \%$ due to rounding. AA, Aortic atresia; $O P V R$, obstructed pulmonary venous return; $M B T S$, modified Blalock-

Taussig shunt; RVPAS, right ventricle-to-pulmonary artery shunt; $M S O F$, multisystem organ failure; GI, gastrointestinal.

no difference between shunt types was found $(P=.34)$ (Table 2). There were also no significant differences in causes of death when further stratifying by the presence or absence of aortic atresia and by the presence or absence of obstructed pulmonary venous return (Tables 3 and 4).

\section{Timing of Death}

The timing of death was analyzed for the entire cohort and for each shunt type. For the overall cohort, the median age at death for subjects dying during the first year was 1.6 months (interquartile range [IQR], 0.6-3.7 months). The median age at death did not differ by shunt type (1.6 months [IQR, 0.8-3.5 months] for the MBTS group vs 1.7 months [IQR, 0.4-4.2 months] for the RVPAS group; $P=.78$ ).

The timing of death was also analyzed by 4 clinically relevant time periods: randomization to Norwood hospitalization discharge, Norwood hospitalization discharge to stage II admission, stage II admission to stage II discharge, and stage II discharge to 12 months (Table 5). The majority of deaths during the first year for the entire cohort, as well as for each shunt type, occurred during the Norwood hospitalization; the next highest number of deaths was in the interstage period between the Norwood hospitalization discharge and the stage II operation. The overall timing of death by the four time intervals differed significantly by shunt type $(P=.02)$, with more early deaths in the MBTS group and more late deaths in the RVPAS group. Within the individual 4 time periods, there were no statistically significant differences in the timing of death by shunt type.

The mortality rate during the Norwood Hospitalization was $16 \%$ ( 88 out of 549 ). During the interstage period from the Norwood hospitalization discharge and the stage II admission, the mortality rate was $11.7 \%$ (54 out of 461 ). The hospital mortality for the stage II operation was 3.9\% (16 out of 407), and for the period from stage II discharge to 12 months the mortality rate was $1.5 \%$ (6 out of 391 ).

\section{Location and Other Aspects of Death}

The location of each death was recorded as occurring at a SVR trial member institution, at an outside hospital, or at home (Table 6). The most common location of death for the overall cohort was at a SVR hospital $(74 \%)$, followed by death at home $(13 \%)$. The inpatient deaths,

TABLE 4. Cardiovascular deaths vs all other causes by the presence or absence of aortic atresia or obstructed pulmonary venous return, overall and by shunt type

\begin{tabular}{|c|c|c|c|c|c|c|c|c|c|c|c|c|}
\hline \multirow[b]{2}{*}{$\begin{array}{c}\text { Cause of } \\
\text { death }\end{array}$} & \multicolumn{2}{|c|}{$\begin{array}{c}\text { Overall } \\
(\mathrm{N}=\mathbf{1 6 4}) \\
(P=.62) \\
\end{array}$} & \multicolumn{2}{|c|}{$\begin{array}{c}\text { MBTS } \\
(\mathbf{n}=95) \\
(P=.99)\end{array}$} & \multicolumn{2}{|c|}{$\begin{array}{c}\text { RVPAS } \\
(\mathbf{n}=69) \\
(P=.34)\end{array}$} & \multicolumn{2}{|c|}{$\begin{array}{c}\text { Overall } \\
(\mathrm{n}=164) \\
(P=.99)\end{array}$} & \multicolumn{2}{|c|}{$\begin{array}{c}\text { MBTS } \\
(\mathrm{n}=95) \\
(P=.74)\end{array}$} & \multicolumn{2}{|c|}{$\begin{array}{c}\text { RVPAS } \\
(\mathrm{n}=69) \\
(P=.99)\end{array}$} \\
\hline & $\begin{array}{c}\mathbf{A A} \\
(\mathbf{n}=\mathbf{1 0 3})\end{array}$ & $\begin{array}{c}\text { No AA } \\
(n=61)\end{array}$ & $\begin{array}{c}\text { AA } \\
(n=62)\end{array}$ & $\begin{array}{c}\text { No AA } \\
(n=14)\end{array}$ & $\begin{array}{r}\text { No OPVR } \\
(\mathbf{n}=150)\end{array}$ & $\begin{array}{c}\text { OPVR } \\
(\mathbf{n}=11)\end{array}$ & $\begin{array}{c}\text { OPVR } \\
(n=14)\end{array}$ & $\begin{array}{c}\text { No OPVR } \\
(n=150)\end{array}$ & $\begin{array}{c}\text { OPVR } \\
(n=11)\end{array}$ & $\begin{array}{c}\text { No OPVR } \\
(n=84)\end{array}$ & $\begin{array}{l}\text { OPVR } \\
(n=3)\end{array}$ & $\begin{array}{c}\text { No OPVR } \\
(n=66)\end{array}$ \\
\hline Cardiovascular & $41(40)$ & $27(44)$ & $24(39)$ & $6(43)$ & $62(41)$ & $5(46)$ & $6(43)$ & $62(41)$ & $5(46)$ & $31(37)$ & $1(33)$ & $31(47)$ \\
\hline $\begin{array}{c}\text { Other cause or } \\
\text { unknown }\end{array}$ & $62(60)$ & $34(56)$ & $38(61)$ & $8(57)$ & $88(59)$ & $6(55)$ & $8(57)$ & $88(59)$ & $6(55)$ & $53(63)$ & $2(67)$ & $35(53)$ \\
\hline
\end{tabular}

Data are presented as $\mathrm{n}(\%)$. Percentages may not total $100 \%$ due to rounding. $A A$, Aortic atresia; $M B T S$, modified Blalock-Taussig shunt; $R V P A S$, right ventricle-to-pulmonary artery shunt; $O P V R$, obstructed pulmonary venous return. 


\begin{tabular}{lccccccc}
\hline & & & & \multicolumn{3}{c}{ Median age at death } \\
\cline { 5 - 8 } \multicolumn{1}{c}{ Time interval } & & & Overall & \multicolumn{2}{c}{ MBTS } & $\begin{array}{c}\text { RVPAS } \\
(\mathbf{n}=\mathbf{6 9})\end{array}$ & $\begin{array}{c}\boldsymbol{P} \text { value } \dagger \\
(\mathbf{n}=\mathbf{9 5})\end{array}$ \\
\hline Randomization to Norwood discharge & $88(54)$ & $48(51)$ & $40(58)$ & $0.69(0.3-1.4)$ & $0.88(0.4-1.5)$ & $0.46(0.2-1.3)$ & .06 \\
Norwood discharge to Stage II admission & $54(33)$ & $39(41)$ & $15(22)$ & $3.0(1.8-4.3)$ & $2.6(1.5-4.2)$ & $3.4(2.8-5.0)$ & .07 \\
Stage II admission to Stage II discharge & $16(10)$ & $6(6)$ & $10(14)$ & $5.3(3.8-6.5)$ & $4.7(3.5-5.7)$ & $5.8(4.2-6.8)$ & .43 \\
Stage II discharge to 12 mo & $6(4)$ & $2(2)$ & $4(6)$ & $8.0(6.6-9.2)$ & $6.5(3.7-9.2)$ & $8.0(7.2-9.0)$ & .83 \\
Total & $164(100)$ & $95(58)$ & $69(42)$ & $1.6(0.6-3.7)$ & $1.6(0.8-3.5)$ & $1.7(0.4-4.2)$ & .78 \\
\hline
\end{tabular}

Data are presented as number (\%) (percentages may not total $100 \%$ due to rounding) or months (interquartile range). MBTS, Modified Blalock-Taussig shunt; RVPAS, right ventricle-to-pulmonary artery shunt. $* P=.02$ for timing of death by shunt type. $\dagger P$ values are from Wilcoxon rank sum test.

including both SVR hospitals and outside hospitals, were further categorized as having occurred in the operating room, the intensive care unit, the general care ward, or the emergency room, with the majority $(71 \%)$ occurring in the intensive care unit (Table 5). In $37 \%$ of deaths (61 out of 164), care was withdrawn and in $24 \%$ (40 out of 164) a limited or full autopsy was performed.

In 29 subjects $(18 \%)$, death was categorized as unexpected, with the initial events occurring outside of a hospital (death may ultimately have occurred in a hospital). Twelve deaths (ie, $41 \%$ of unexpected deaths, $7 \%$ of all deaths in the SVR trial) were preceded by a prodrome, 16 were not preceded by a prodrome, and in 1 death the presence of a prodrome was unknown. Of those with a prodrome, 4 were described as having poor oral intake or vomiting; 3 as having fussiness; 2 as having diarrhea; 1 as having cyanosis; 1 as having a combination of poor oral intake, fussiness, and diarrhea; and 1 with a combination of fever and increased work of breathing. Of those with a prodrome, 3 subjects had been evaluated by their local physician for their symptoms.

\section{DISCUSSION}

The mortality of infants enrolled in the SVR trial is similar to previously published reports. ${ }^{1-6}$ The first year of life has a high risk for mortality, especially during hospitalization related to the Norwood procedure and the interstage period leading up to the stage II procedure.

TABLE 6. Location of patient death (overall $N=164$; inpatient $\mathrm{n}=140$ )

\begin{tabular}{lc}
\hline \multicolumn{1}{c}{ Location of death } & $\mathbf{n}(\%)$ \\
\hline SVR trial member hospital & $121(74)$ \\
Home & $22(13)$ \\
Outside hospital & $19(12)$ \\
Unknown & $2(1)$ \\
Any hospital intensive care unit & $99(71)$ \\
Unknown location in a hospital & $21(15)$ \\
Hospital emergency room & $10(7)$ \\
Hospital operating room & $8(6)$ \\
Hospital general care floor & $2(1)$ \\
\hline
\end{tabular}

SVR, Single ventricle reconstruction.
This is the first systematic report of the causes of death in a large cohort of infants with hypoplastic left heart syndrome and related single ventricle lesions undergoing staged repair. Evaluating the circumstances surrounding these mortalities may in turn identify potential areas where changes in medical management could improve outcomes.

The results of our analysis of mortality during the first year after the Norwood procedure showed that the predominant cause of death was cardiovascular and those with an MBTS were more likely to die during the Norwood hospitalization than those with an RVPAS. The majority of deaths occurred in a hospital, and of those, the majority occurred in an intensive care unit. In more than one-third of cases, the family requested that care be withdrawn.

\section{Cause of Death}

It is not surprising that the primary cause of death was cardiovascular. In many of the cases in the cardiovascular category, the underlying mechanism was myocardial failure and low cardiac output. In addition, the majority of deaths occurred during hospitalization for the Norwood procedure. This combination of findings suggests that better forms of myocardial protection or better ways to enhance postoperative myocardial performance are needed.

Surgical complications were the fifth most common cause of death and provide another example of the potential benefit of modification of perioperative management or technique. Although beyond the scope of our study, the rate of death due to surgical complications could be compared by practice patterns or by center in an attempt to identify the common practices associated with the lowest surgical mortality rates. These best practices could then be disseminated to all institutions. Successful approaches for identifying and sharing best practices at high-performing centers have been established in other disciplines, such as adult cardiovascular surgery, infection control, and cystic fibrosis, and are now beginning to be applied in congenital heart surgery, as well. ${ }^{11-14}$

The cause of death, either overall or when stratified by shunt type, was not affected by the presence or absence of aortic atresia or obstructed pulmonary venous return. This 
finding may be somewhat surprising, because one may have hypothesized that aortic atresia would have contributed to the preponderance of cardiovascular-related deaths and obstructed pulmonary venous return to a high incidence of pulmonary vascular category deaths. Whether or not aortic atresia represents a risk factor for survival remains controversial, with some centers reporting a correlation, whereas others do not. ${ }^{15,16}$ The relationship of aortic atresia and other potential risk factors to mortality in the SVR trial is currently being analyzed. Obstructed pulmonary venous return has also been inconsistently associated with mortality in previous publications. ${ }^{16,17}$ Obstruction to pulmonary venous return may be particularly important as a patient progresses to the stage II and Fontan procedures, where low pulmonary vascular resistance is crucial. ${ }^{17}$ Our analysis was limited to the 12 months following randomization and it is possible that the adverse effects of obstructed pulmonary venous return may become evident only in later follow-up. In addition, the relatively low incidence of obstructed pulmonary venous return in the cohort of subjects who died during the SVR trial period $(\mathrm{n}=14)$ limits the power to detect differences.

\section{Timing of Death}

In the SVR trial, as in other reports, the highest risk of dying during the first year was during hospitalization for the Norwood procedure. However, the interval from Norwood hospitalization discharge to the stage II procedure is a high-risk period, as well. ${ }^{5,6,18}$ Overall, $33 \%$ of deaths (54 out of 164) during the 12-month duration of the trial occurred during this interstage period, representing an overall trial mortality rate between the first and second stages of $11.7 \%$ (54 of 461). Whether or not home monitoring programs can affect this interstage mortality remains controversial. Recently, some institutions have reported small case series demonstrating a decrease in interstage mortality with the implementation of a formal home monitoring program, although others have not. ${ }^{18-20}$ Furthermore, it remains unknown if these patients would have breached criteria of a home monitoring program or if immediate hospital admission or any intervention would have been successful in preventing death.

\section{Location and Other Aspects of Death}

Analysis of the location of death provides another opportunity to improve outcomes. Twenty percent of deaths (32 out of 164) occurred either at home or in a hospital emergency department. Of these outpatient deaths, 29 were unexpected, occurring in patients who were otherwise doing well. This group of patients is of particular interest because their deaths may have been potentially preventable, if an early warning signal could have been detected. The 12 subjects who manifested a prodrome before their fatal event may represent a subset in which such a signal was present. It is not possible to know, from the level of data available for our analysis, if other subjects who died unexpectedly also had prodromes that could not be identified retrospectively. In addition, it is unknown how many surviving subjects in the SVR trial had similar signs and symptoms at home without a subsequent lethal event. One may postulate that improvements in parent or local physician education may have averted some deaths. A recent survey of 376 emergency department physicians determined that most $(72 \%)$ were unsure of the acceptable range of arterial oxygen saturation for infants with a single ventricle, and $58 \%$ were "uncomfortable" or "worried" about their treatment. ${ }^{21}$ Despite these concerns, 59\% deemed education in single ventricle physiology as low priority, likely due to the low frequency of encounters with these unique patients.

\section{CONCLUSIONS}

Remarkable progress has been made in the care of patients with single ventricles with systemic outflow obstruction, a universally fatal lesion just 3 decades ago. However, despite this success, there continue to be high rates of attrition throughout the first year of life. Analysis of the cause of death of these infants may be useful in decreasing this mortality rate. The data regarding the etiology of the deaths in the SVR trial suggest that efforts to improve postoperative myocardial performance may be helpful in improving outcomes. Analyzing variations in care and developing best practices may also decrease mortality. The continued high interstage attrition, as well as the frequent finding of a prodrome before unexpected deaths, may suggest that a home monitoring program or providing parents and primary care physicians with a list of concerning signs and symptoms may be helpful. Through better understanding of the mechanisms of death, we hope to devise improved surgical techniques, inpatient and outpatient management, and family and health care provider education to continue to optimize outcomes for this challenging group of patients.

\section{References}

1. Tabbutt S, Dominguez TE, Ravishankar C, Marino BS, Gruber PJ, Wernovsky G, et al. Outcomes after the stage I reconstruction comparing the right ventricular to pulmonary artery conduit with the modified Blalock Taussig shunt. Ann Thorac Surg. 2005;80:1582-90; discussion 1590-1.

2. Mahle WT, Cuadrado AR, Tam VK. Early experience with a modified Norwood procedure using right ventricle to pulmonary artery conduit. Ann Thorac Surg. 2003;76:1084-8; discussion 1089.

3. Pizarro C, Malec E, Maher KO, Januszewska K, Gidding SS, Murdison KA, et al. Right ventricle to pulmonary artery conduit improves outcome after stage I Norwood for hypoplastic left heart syndrome. Circulation. 2003;108(Suppl 1): II155-60.

4. Sano S, Ishino K, Kado H, Shiokawa Y, Sakamoto K, Yokota M, et al. Outcome of right ventricle-to-pulmonary artery shunt in first-stage palliation of hypoplastic left heart syndrome: a multi-institutional study. Ann Thorac Surg. 2004;78: 1951-7; discussion 1957-8. 
5. Hehir DA, Dominguez TE, Ballweg JA, Ravishankar C, Marino BS, Bird GL, et al. Risk factors for interstage death after stage 1 reconstruction of hypoplastic left heart syndrome and variants. J Thorac Cardiovasc Surg. 2008;136:94-9, 99.e1-3.

6. Ohye RG, Sleeper LA, Mahony L, Newburger JW, Pearson GD, Lu M, et al. Comparison of shunt types in the Norwood procedure for single-ventricle lesions. N Engl J Med. 2010;362:1980-92.

7. Charpie JR, Dekeon MK, Goldberg CS, Mosca RS, Bove EL, Kulik TJ. Serial blood lactate measurements predict early outcome after neonatal repair or palliation for complex congenital heart disease. J Thorac Cardiovasc Surg. 2000;120: 73-80.

8. Ohye RG, Ludomirsky A, Devaney EJ, Bove EL. Comparison of right ventricle to pulmonary artery conduit and modified Blalock-Taussig shunt hemodynamics after the Norwood operation. Ann Thorac Surg. 2004;78:1090-3.

9. Cua CL, Thiagarajan RR, Gauvreau K, Lai L, Costello JM, Wessel DL, et al. Early postoperative outcomes in a series of infants with hypoplastic left heart syndrome undergoing stage I palliation operation with either modified Blalock-Taussig shunt or right ventricle to pulmonary artery conduit. Pediatr Crit Care Med. 2006; 7:238-44.

10. Ohye RG, Gaynor JW, Ghanayem NS, Goldberg CS, Laussen PC, Frommelt PC, et al. Design and rationale of a randomized trial comparing the Blalock-Taussig and right ventricle-pulmonary artery shunts in the Norwood procedure. $J$ Thorac Cardiovasc Surg. 2008;136:968-75.

11. Johnson SH, Theurer PF, Bell GF, Maresca L, Leyden T, Prager RL. A statewide quality collaborative for process improvement: internal mammary artery utilization. Ann Thorac Surg. 2010;90:1158-64; discussion 1164.

12. Furuya EY, Dick A, Perencevich EN, Pogorzelska M, Goldmann D, Stone PW. Central line bundle implementation in US intensive care units and impact on bloodstream infections. PLoS One. 2011;6:e15452.

13. Flume PA, Mogayzel PJ Jr, Robinson KA, Goss CH, Rosenblatt RL, Kuhn RJ, et al. Cystic fibrosis pulmonary guidelines: treatment of pulmonary exacerbations. Am J Respir Crit Care Med. 2009;180:802-8.

14. Kugler JD, Beekman Iii RH, Rosenthal GL, Jenkins KJ, Klitzner TS, Martin GR, et al. Development of a pediatric cardiology quality improvement collaborative: from inception to implementation. From the Joint Council on Congenital Heart Disease Quality Improvement Task Force. Congenit Heart Dis. 2009;4:318-28.

15. Vida VL, Bacha EA, Larrazabal A, Gauvreau K, Dorfman AL, Marx G, et al. Surgical outcome for patients with the mitral stenosis-aortic atresia variant of hypoplastic left heart syndrome. J Thorac Cardiovasc Surg. 2008;135:339-46.

16. Stasik CN, Gelehrter S, Goldberg CS, Bove EL, Devaney EJ, Ohye RG. Current outcomes and risk factors for the Norwood procedure. J Thorac Cardiovasc Surg. 2006;131:412-7.

17. Bove EL, Lloyd TR. Staged reconstruction for hypoplastic left heart syndrome. Contemporary results. Ann Surg. 1996;224:387-94; discussion 394-5.

18. Ghanayem NS, Hoffman GM, Mussatto KA, Cava JR, Frommelt PC, Rudd NA, et al. Home surveillance program prevents interstage mortality after the Norwood procedure. J Thorac Cardiovasc Surg. 2003;126:1367-77.

19. Furck AK, Uebing A, Hansen JH, Scheewe J, Jung O, Fischer G, et al. Outcome of the Norwood operation in patients with hypoplastic left heart syndrome: a 12year single-center survey. J Thorac Cardiovasc Surg. 2010;139:359-65.

20. Petit CJ, Frasier CD, Mattamal R, Slesnick TC, Cephas CE, Ocampo EC. The impact of a dedicated single-ventricle home-monitoring program on interstage somatic growth, interstage attrition, and 1-year survival. J Thorac Cardiovasc Surg. 2011;142:1358-66.

21. Cashen K, Gupta P, Lieh-Lai M, Mastropietro C. Infants with single ventricle physiology in the emergency department: are physicians prepared? J Pediatr. 2011;159:273-7.e1.

\section{APPENDIX 1. MEMBERS OF THE SINGLE VENTRICLE RECONSTRUCTION TRIAL TEAM}

National Heart, Lung, and Blood Institute: Gail Pearson, Victoria Pemberton, Rae-Ellen Kavey,* Mario Stylianou, and Marsha Mathis.*

Network Chair: Lynn Mahony, University of Texas Southwestern Medical Center.

Data Coordinating Center: (New England Research Institutes) Lynn Sleeper (PI), Sharon Tennstedt (PI), Steven
Colan, Lisa Virzi,* Patty Connell,* Victoria Muratov, Lisa Wruck,* Minmin Lu, Dianne Gallagher, Anne Devine,* Julie Schonbeck, Thomas Travison,* and David F. Teitel.

Core Clinical Site Investigators: (Children's Hospital Boston) Jane W. Newburger (PI), Peter Laussen, Pedro del Nido, Roger Breitbart, Jami Levine, Ellen McGrath, Carolyn Dunbar-Masterson, John E. Mayer, Jr, Frank Pigula, Emile A. Bacha, and Francis Fynn-Thompson; (Children's Hospital of New York) Wyman Lai (PI), Beth Printz,* Daphne Hsu,* William Hellenbrand, Ismee Williams, Ashwin Prakash,* Seema Mital,* Ralph Mosca,* Darlene Servedio,* Rozelle Corda, Rosalind Korsin, and Mary Nash*; (Children's Hospital of Philadelphia) Victoria L. Vetter (PI), Sarah Tabbutt,* J. William Gaynor (study co-chair), Chitra Ravishankar, Thomas Spray, Meryl Cohen, Marisa Nolan, Stephanie Piacentino, Sandra DiLullo,* and Nicole Mirarchi; (Cincinnati Children's Medical Center) D. Woodrow Benson (PI), Catherine Dent Krawczeski, Lois Bogenschutz, Teresa Barnard, Michelle Hamstra, Rachel Griffiths, Kathryn Hogan, Steven Schwartz,* David Nelson, and Pirooz Eghtesady*; (North Carolina Consortium: Duke University, East Carolina University, Wake Forest University) Page A. W. Anderson $(\mathrm{PI}){ }^{\dagger}$ Jennifer Li (PI), Wesley Covitz, Kari Crawford,* Michael Hines, James Jaggers,* Theodore Koutlas, Charlie Sang, Jr, Lori Jo Sutton, and Mingfen Xu; (Medical University of South Carolina) J. Philip Saul (PI), Andrew Atz, Girish Shirali, Scott Bradley, Eric Graham, Teresa Atz, and Patricia Infinger; (Primary Children's Medical Center and the University of Utah, Salt Lake City) L. LuAnn Minich (PI), John A. Hawkins, ${ }^{\dagger}$ Michael Puchalski, Richard V. Williams, Peter C. Kouretas, Linda M. Lambert, Marian E. Shearrow, and Jun A. Porter*; (Hospital for Sick Children, Toronto) Brian McCrindle (PI), Joel Kirsh, Chris Caldarone, Elizabeth Radojewski, Svetlana Khaikin, Susan McIntyre, and Nancy Slater; (University of Michigan) Caren S. Goldberg (PI), Richard G. Ohye (study chair), Cheryl Nowak*; (Children's Hospital of Wisconsin and Medical College of Wisconsin) Nancy S. Ghanayem (PI), James S. Tweddell, Kathleen A. Mussatto, Michele A. Frommelt, Peter C. Frommelt, and Lisa YoungBorkowski.

Auxiliary Sites: (Children's Hospital Los Angeles) Alan Lewis (PI), Vaughn Starnes, and Nancy Pike; (The Congenital Heart Institute of Florida) Jeffrey P. Jacobs (PI), James A. Quintessenza, Paul J. Chai, David S. Cooper,* J. Blaine John, James C. Huhta, Tina Merola, and Tracey Griffith; (Emory University) William Mahle (PI), Kirk Kanter, Joel Bond,* Jeryl Huckaby; (Nemours Cardiac Center) Christian Pizarro (PI), Carol Prospero, Julie Simons, Gina Baffa, and Wolfgang A. Radtke; (University of Texas Southwestern Medical Center) Ilana Zeltzer (PI), Tia Tortoriello,* Deborah McElroy, and Deborah Town. 
Angiography Core Laboratory: (Duke University) John Rhodes and J. Curt Fudge.

Echocardiography Core Laboratories: (Children's Hospital of Wisconsin) Peter Frommelt; (Children's Hospital Boston) Gerald Marx.

Genetics Core Laboratory: (Children's Hospital of Philadelphia) Catherine Stolle.
Protocol Review Committee: Michael Artman (chair), Erle Austin, Timothy Feltes, Julie Johnson, Thomas Klitzner, Jeffrey Krischer, and G. Paul Matherne.

Data and Safety Monitoring Board: John Kugler (chair), Rae-Ellen Kavey (executive secretary), David J. Driscoll, Mark Galantowicz, Sally A. Hunsberger, Thomas J. Knight, Holly Taylor, and Catherine L. Webb. 